\title{
Educação Patrimonial, Arqueologia e Narrativas Decoloniais
}

\author{
SALLES, Sandro Guimarães de ${ }^{1}$ \\ FEITOSA, Saulo Ferreira ${ }^{2}$
}

\section{RESUMO}

O presente artigo é fruto das pesquisas desenvolvidas no projeto Educação Patrimonial e Cartografia Arqueológica do Agreste Central de Pernambuco, tendo como objetivo discutir as possibilidades de aproximação entre a arqueologia e o pensamento pós-colonial, com ênfase na bioarqueologia. Em um primeiro momento, discutimos a noção de arqueologia viva que fundamenta nossa pesquisa, apresentando suas bases epistêmicas, assentadas no pensamento pós-colonial. Em um segundo momento, discutimos os aportes decoloniais da bioarqueologia, bem como sua possibilidade de revelar modos outros de vida nas sociedades originárias. Apresentamos o Bem Viver como um desses modos, podendo ser identificado nas mais variadas culturas, nos mais distintos períodos históricos e em diferentes regiões do globo terrestre. Por fim, discutindo as possibilidades de contribuições da bioarqueologia para as pesquisas arqueológicas no Agreste Pernambucano, abordando o caso do Sítio Furna do Estrago, no Brejo da Madre de Deus/PE.

Bioarqueologia. Educação Patrimonial. Agreste Pernambucano.

\section{PATRIMONIAL EDUCATION, ARCHAEOLOGY AND DECOLONIAL NARRATIVES}

This article is the result of researches developed in the project Educação Patrimonial e Cartografia Arqueológica do Agreste Central de Pernambuco (Patrimonial Education and Archaeological Cartography of Central Harsh Region of Pernambuco), aiming to discuss the possibilities of approaching archeology and postcolonial thought, with an emphasis on bioarchaeology. At first, we discuss the notion of living archeology that underlies our research, presenting its epistemic foundations, based on postcolonial thought. In a second moment, we discuss decolonial contributions of bioarchaeology, as well as its possibility of revealing other ways of life in the original societies. We present Well Living (Vivir bien) as one of these ways, identified in the most varied cultures, in the most distinct historical periods and in different regions of the world. Finally, discussing the possibilities of bioarchaeological contributions to archaeological research in the northest harsh region of Pernambucano, addressing the case of the Sítio Furna do Estrago, a countryside site in the city of Brejo da Madre de Deus.

\footnotetext{
${ }^{1}$ UFPE - Programa de Pós-Graduação em Educação Contemporânea. Sandro.ufpe@gmail.com

${ }^{2}$ UFPE - Programa de Pós-Graduação em Educação Contemporânea. sauloffeitosa@gmail.com
} 
Bioarchaeology. Patrimonial Education. Harsh Region of Pernambuco.

\section{INTRODUÇÃO}

Este trabalho é fruto das pesquisas desenvolvidas no projeto Educação Patrimonial e Cartografia Arqueológica do Agreste Central de Pernambuco, que reúne pesquisadores de diferentes áreas, interessados em pesquisar os sítios arqueológicos da referida região. Partimos do pressuposto que esses sítios eram pesquisados, majoritariamente, seguindo tendências e valores epistêmicos e metodológicos dominantes nas ciências humanas e sociais, onde o diálogo com a comunidade e a preocupação com a melhoria da sua qualidade de vida são minimizados. Seria necessário, portanto, repensar as epistemologias e métodos que dissociam teoria e prática, não concebendo as pesquisas sociais como ações políticas. Com efeito, as primeiras pesquisas na região, que têm início ainda na década de 1960, seguindo os paradigmas dominantes na época, apesar de grande contribuição para a arqueologia local, poucos resultados apresentaram em relação à participação e melhoria de vida da comunidade do entorno dos sítios pesquisados, mantendo um modelo pouco dialógico na relação entre a academia e as comunidades das áreas pesquisadas. Nessa perspectiva, o "outro" permanece ausente da construção dos discursos científicos, estando presente apenas de modo objetivado. Essa ausência radical do "outro" postularia, segundo Quijano (2007), uma imagem atomística de existência social em geral, negando a ideia de totalidade social.

Apesar de todo o conhecimento produzido em um espaço de quase dez décadas, a importância da região para as pesquisas arqueológicas ainda é pouco conhecida, inclusive pelos próprios moradores. Estes, em geral, não dispõem de informações, nem orientações sobre os bens arqueológicos. Mesmo nas pesquisas que tiveram certo impacto na região, sendo conhecida da maioria dos(as) moradores(as), como a desenvolvida na Furna do Estrago, por exemplo, o retorno à comunidade ainda é exíguo. Temos observados que essa ausência de diálogo e de ações concretas, na maioria das pesquisas que partem do discurso sobre o patrimônio cultural nacional - o que inclui, notadamente, a antropologia e a arqueologia -, acontece mesmo sendo a educação patrimonial um dos conceito-chaves empregados. Em muitos casos, a concepção de educação patrimonial tende a limitar-se à utilização dos moradores do entorno na preservação dos sítios arqueológicos. Ainda que a preservação seja, sem dúvida, fundamental, as ações de educação patrimonial junto à comunidade devem ser mais amplas e verdadeiramente dialógicas.

O presente artigo tem como objetivo discutir as possibilidades de aproximação entre a arqueologia e o pensamento pós-colonial. Em um primeiro momento, refletimos sobre a noção de arqueologia viva, que fundamenta nossa 
pesquisa, apresentando suas bases epistêmicas, assentadas no pensamento pós-colonial. Em um segundo momento, discutimos os aportes decoloniais da bioarqueologia, bem como sua possibilidade de revelar modos outros de vida nas sociedades originárias. Em seguida, abordamos o Bem Viver, como um desses modos, encontrados nas mais variadas culturas, nos mais distintos períodos históricos e em diferentes regiões do globo terrestre. Na parte final do trabalho discutimos as possibilidades de contribuições da bioarqueologia para as pesquisas arqueológicas no Agreste Pernambucano, partindo do caso do Sítio Furna do Estrago, no Brejo da Madre de Deus/PE.

\section{Por uma arqueologia viva}

O que estamos aqui chamando de arqueologia viva é a necessidade de, para além de uma perspectiva meramente descritiva, fazer perguntas outras a partir dos registros arqueológicos, ou seja, partindo da análise propriamente arqueológica, dialogando com a antropologia, história, educação e outras áreas das ciências humanas e sociais. Perguntamos-nos, por exemplo, qual a relação desses registros com as populações originárias encontradas na região, considerando que a arqueologia também se constitui em fonte privilegiada de informações sobre o modo de vida de antigas sociedades, produzindo informações sobre os mais variados conhecimentos das diversas culturas estudadas. Essas e outras questões são aqui discutidas tendo como referência o pensamento pós-colonial, que vai sugerir uma perspectiva epistêmicoconceitual outra para pensar o patrimônio arqueológico estudado e a concepção de educação patrimonial, além de problematizar a própria concepção de pesquisa científica e a relação do pesquisador com a comunidade de entorno dos sítios pesquisados. Partindo do conceito de geopolítica do conhecimento, os estudos pós-coloniais postulam que as ciências modernas "encerram um 'regime de verdade' que reproduz sempre e inapelavelmente as relações de poder existentes" (COSTA, 2010, p. 29). Desse modo, conhecimentos e epistemologias produzidos fora da lógica operacional das ciências modernas seriam considerados menores, ilegítimos, enquanto a teoria dos sujeitos brancos, europeus seria considerada a única válida. Essa geopolítica, através de práticas epistemicidas, teria o controle do fazer científico, de modo que "todas as disciplinas, sem exceção, privilegiam os pensadores e teorias ocidentais, sobretudo aquelas dos homens europeus e/ou euro-norte-americanos" (GROSFOGUEL, 2015, p. 32). Essa naturalização de um lugar de fala privilegiado nas pesquisas científicas revela como a política identitária dominante não se manifesta como tal, mas através de conceitos supostamente universais e abstratos. Neste sentido, seria como se essa política identitária dominante "falasse de um lugar-nenhum tornando familiar que cada qual se veja, sempre, de um lugar determinado, enquanto haveria aqueles que falam como se fossem do mundo e não de nenhuma parte 
específica" (PORTO GONÇALVES, 2005, p. 3).

$\mathrm{Na}$ perspectiva dos estudos pós-coloniais, questiona-se o lugar (epistêmico e político) reservado nas ciências às sociedades e aos indivíduos situados fora do mundo eurocêntrico. Parte-se, assim, de uma perspectiva que põe em cheque o locus de enunciação eurocentrado como única forma válida de ser e de produzir conhecimento, que não concebe os sujeitos da pesquisa (interlocutores, nativos) como agentes de sua história e construtores de suas identidades.

A pesquisa que deu origem ao presente artigo, portanto, remete a uma arqueologia viva, dinâmica e comunitária, que pode produzir narrativas decoloniais, distanciando-se da perspectiva que opõe teoria e prática, invisibilizando os processos identitários e culturais locais. Também nos apoiamos na concepção de González-Ruibal (2009), que defende uma Arqueologia (ou Etnoarqueologia) do presente, comprometida com a ética, onde os sujeitos da pesquisa deixam de ser pensados como meros produtores de dados para as analogias arqueológicas.

\section{Aportes decoloniais da bioarqueologia}

Tendo como finalidade estudar a variabilidade biocultural humana, a bioarqueologia, também denominada Antropologia Biológica, está voltada para os estudos sobre a origem e os processos que envolvem essa variabilidade, considerando, sobretudo, os aspectos históricos e geográficos. Partindo sempre do contexto cultural, a bioarqueologia desenvolve estudos tanto com populações antigas, como com grupos culturais contemporâneos.

As pesquisas que envolvem grupos humanos do passado fazem uso de tecidos mumificados, ossos e dentes, procurando identificar as relações existentes entre esses e os contextos ambientais, assim como outros elementos próprios da arqueologia:

O estudo bioarqueológico de esqueletos subadultos, isto é, com ossos e dentes em estágio de desenvolvimento, possibilita a obtenção de informações sobre as instâncias da vida biológica e sociocultural desses indivíduos, a partir da dieta, idade no momento da morte, sexo, ancestralidade ou origem biogeográfica, bem como sobre outros fatores que tenham exposto os jovens indivíduos a traumas ou doenças nos diversos estágios de crescimento ao decorrer das suas curtas vidas. (SOLARI et al., 2018, p. 105).

Notícia divulgada no dia 12 de março de 2019, no site da revista Science, informa que 130 paleopatologistas, bioarqueologistas, geneticistas e especialistas em doenças raras estiveram reunidos em Berlin e os vários casos 
apresentados dentro da linha de pesquisa denominada Bioarqueologia do Cuidado revela que "as pessoas com doenças raras geralmente desfrutavam do apoio de suas sociedades, sobreviviam até a idade adulta e eram enterradas com suas comunidades, não como forasteiros marginalizados". Algumas pesquisas identificaram que os locais de sepultamento dessas pessoas, algumas delas anãs ou portadoras da fenda palatina, eram destinados aos homens e mulheres que usufruíam de status elevado naquelas sociedades.

Essas descobertas desconstroem as narrativas construídas pelo discurso da modernidade, segundo o qual as sociedades ditas primitivas rejeitavam as pessoas com deficiência, inclusive sob a afirmação de que aquelas eram excluídas, abandonadas e até sacrificadas em rituais. Identificamos nesses achados alguns indicativos que nos possibilitam afirmar ser possível a produção de conhecimento arqueológico numa perspectiva decolonial.

Algo que nos chama a atenção é que diferentemente da perspectiva apontada por essas pesquisas arqueológicas envolvendo povos que viveram cerca de 5000 anos a. C., nas denominadas "grandes civilizações" da antiguidade clássica, o tratamento dado às pessoas com deficiência era exatamente o oposto. Na Grécia e em Roma elas eram consideradas um estorvo. Em suas respeitadas obras, Platão (A República) e Aristóteles (A Política) recomendam a exclusão daquelas pessoas que eram consideradas inaptas, como forma de organizar melhor as cidades:

\begin{abstract}
Pegarão então os filhos dos homens superiores, e levá-los-ão para o aprisco, para junto de amas que moram à parte num bairro da cidade; os dos homens inferiores, e qualquer dos outros que seja disforme, escondê-los-ão num lugar interdito e oculto, como convém (A República, Livro IV, 460 c). (PLATÃO, 2010, p. 155).

Quanto a rejeitar ou criar os recém-nascidos, terá de haver uma lei segundo a qual nenhuma criança disforme será criada (A Política, Livro VII, Capítulo XIV, 1335 b). (ARISTÓTELES, 2003, p. 150).
\end{abstract}

Em Roma, a Lei das Doze Tábuas ${ }^{3}$ (Lex Duodecim Tabularum), 450 a.C, na Tábua IV, referente ao Patria Potestas, assegurava ao pai o direito de decidir sobre a vida do filho. Cícero (106-46 a.C.), em De legibus, se posiciona da seguinte forma sobre a matéria: "uma criança horrivelmente deformada deve ser rapidamente morta, como ordenam as Doze Tábuas" (De legibus, 3.8.19).

\footnotetext{
3 "Foi gravada em 12 tábuas de bronze, fixadas no forum. Transformou o Direito Romano consuetudinário em direito escrito, do conhecimento de todos, patrícios e plebeus, aplicável a ambos" (Gusmão, 2002, p. 298).
} 


\section{Arqueologia e Bem viver}

O Bem Viver representa uma proposta de vida em sociedade que tem como referência as sociedades originárias dos povos ameríndios. $\mathrm{Na}$ atualidade, essa propositura tem sido bastante evidenciada nas discussões e formulações políticas de alguns países sul americanos, a exemplo da Bolívia, onde é também denominado Suma Qamaña, em língua Aymara e do Equador, com a denominação de Sumak Kwasay, em língua Quíchua. Compreendido enquanto categoria filosófica que enuncia uma proposição de vida boa, o Bem Viver promove uma mudança de paradigma pelo fato de defender a centralidade da Natureza. Isso implica numa compreensão da relação de equidade entre as espécies humanas e não humanas, no reconhecimento de que todas elas coabitam a Casa Comum, o Planeta Terra.

As filosofias dos povos originários são os principais repositórios dos ensinamentos do Bem Viver. Por outro lado, como mencionamos, a arqueologia também se constitui em fonte privilegiada de informações sobre 0 modo de vida de antigas sociedades, produzindo os mais variados conhecimentos sobre as diversas culturas estudadas. Diante disso, nos propusemos a refletir sobre as possibilidades de haver uma aproximação entre os achados arqueológicos e os indicadores de vida boa presentes na perspectiva apontada pelo Bem Viver. Para tanto, adotamos um entendimento de que, independentemente de sua denominação, pelo fato de corresponder a uma categoria filosófica, o que tem sido chamado de Bem Viver corresponde a diversos modos e filosofias, identificados nas mais variadas culturas, nos mais distintos períodos históricos e em diferentes regiões do globo terrestre.

No intuito de corroborar essa compreensão, recorremos às reflexões realizas pelo biólogo Humberto Maturana sobre o modelo matrístico de cultura. Chama-nos a atenção o fato de haver aproximação entre os conteúdos principiológicos de uma proposta de vida europeia no passado com as experiências ameríndias do Bem Viver. As informações sobre a existência dessa cultura são provenientes de estudos arqueológicos realizados na região do Danúbio, dos Bálcãs e da Egea.

Não temos acesso direto a tal cultura; porém, penso que a rede de conversações que a constituía pode ser reconstruída a partir do que é revelado na vida quotidiana daqueles povos que ainda a vivem e pelas conversações não patriarcais ainda presentes nas malhas da rede de conversações patriarcais que constitui nossa cultura patriarcal hodierna. Assim, penso que devamos deduzir, a partir dos restos arqueológicos mencionados, que o povo que vivia na Europa, entre sete e cinco mil anos antes de Cristo, era composto por agricultores e coletores que não construíam fortificações em seus povoados, que não apresentavam diferenças hierárquicas entre túmulos 
de homens e de mulheres, ou entre túmulos de homens ou entre túmulos de mulheres (MATURANA, 1993, p. 25-26).

O conceito de matrística se diferencia do conceito de matriarcal. A concepção matrística refere-se a um modelo de sociedade no qual predominam as relações construídas com base no cuidado e não na dominação,

[...] a mulher tem uma presença mística, que implica a coerência sistêmica acolhedora e liberadora do maternal fora do autoritário e do hierárquico. A palavra matrístico, portanto, é contrária à palavra matriarcal, que significa o mesmo que a palavra patriarcal, em uma cultura na qual as mulheres têm um papel dominante. [...] a palavra matrístico é usada intencionalmente, para referir uma cultura na qual homens e mulheres podem participar de um modo de vida centrado em uma cooperação não hierárquica, precisamente porque a figura feminina representa a consciência não hierárquica do mundo natural a que pertencemos os seres humanos, em uma relação de participação e confiança, não de controle nem de autoridade, e na qual a vida quotidiana é vivida em uma coerência não hierárquica com todos os seres viventes, mesmo na relação predador-presa (MATURANA, 1993, p. 19).

No intuito de identificar os indicadores que diferenciam uma cultura patriarcal de uma cultura matrística, Maturana estabelece uma comparação entre os valores intrínsecos a cada modelo. O modelo patriarcal se fundamenta em "um modo de coexistência que valoriza a guerra, a competição, a luta, as hierarquias, a autoridade, o poder, a procriação, o crescimento, a apropriação dos recursos e a justificação racional do controle e da dominação dos outros por meio da apropriação da verdade" (MATURANA, 1993, p. 24). Uma sociedade fundada no modelo matrístico, por sua vez, se destaca pela "participação, inclusão, colaboração, compreensão, acordo, respeito e coinspiração" (MATURANA, 1993, p. 27).

É importante ter em conta que o autor aqui referenciado adota uma compreensão de humanidade que se constitui pela linguagem e a convivência. Outro aspecto que considera determinante para o desenvolvimento da pessoa humana é a emoção. Através dela o ser humano estabelece as suas relações. Dessa forma, a capacidade de viver, de conviver depende da possibilidade de se emocionar. Isso representa uma negação do domínio da razão que se impôs como a única forma de se buscar uma compreensão de vida boa, referenciada por valores éticos universais. Pode-se, portanto, inferir que o Bem Viver se concretiza através do Bem Conviver, sendo na convivialidade que as construções históricas das relações sociais promovem experiências de vida boa.

Contudo, deve-se indagar se esses valores matrísticos podem ser traduzidos para as sociedades humanas da atualidade. A dúvida advém do 
longo período de imposição do modelo de produção capitalista no mundo que produziu uma cultura patriarcal de dominação, sustentada pelo fundamentalismo do mercado, onde a vida humana é compreendida numa perspectiva economicista. Mesmo se tratando de comunidades indígenas, não se pode negar a influência sofrida pelos agentes externos, sejam eles estatais ou outros. Procurando entender como opera uma economia que tenha como inspiração a filosofia matrística, Arruda faz a seguinte afirmação:

Traduzida para as relações econômicas e políticas, a cultura matrística promove a democracia econômica e política, entendida como cooperação, partilha e co-participação enquanto partes das emoções fundamentais que inspiram a ação de superar a escassez, enquanto distribuição participativa em vez de apropriação e centralização. Este é o momento que pode ser chamado de uma Socioeconomia Mista, no qual dois modos diferentes de produção co-existem, um informado pela cultura patriarcal, o outro pela cultura matrística (ARRUDA, 2004, p.05).

Assim como no modelo matrístico de sociedade, a proposição do Bem viver está embasada numa concepção de ética cósmica que promove "uma reintegração da natureza na história, como inerente ao ser social" (DÁVALOS, 2010, p. 69). David Choquehuanca (138), um dos maiores estudiosos e defensores do bem viver na Bolívia, elaborou um rol de 25 postulados para se compreender o seu significado. Um deles enuncia que na concepção do Suma Qamaña, os direitos cósmicos estão acima dos direitos humanos.

$\mathrm{Na}$ base de tal afirmação está o argumento ético-filosófico de que a natureza é fonte de vida (inclusive a humana), sendo o ser humano parte pensante da realidade existente na natureza, que sem ela não pode existir. Como consequência, conclui-se que a natureza é sujeito de direitos. Esses direitos não dependem da mediação humana, posto que o gênero humano não é o dono da natureza (FEITOSA, 2015, p. 128).

$\mathrm{Na}$ economia do bom viver, o valor de uso está acima do valor de troca, invertendo a lógica capitalista que justifica a acumulação. Nas relações de poder, deve-se observar o mandado obediencial, por isso as pessoas que exercem algum mandato deverão aprender a "mandar obedecendo", que na prática significa escutar os seus governados e respeitar suas opiniões, num exercício pleno de controle social, diferente do modelo de controle exercido pelos conselhos, que em geral não produzem a eficácia esperada. Somam-se a essas muitas outras proposições, para as mais diferentes áreas da vida humana (FEITOSA, 2015, p. 129).

\section{A Furna do Estrago}


$\mathrm{Na}$ região Agreste de Pernambuco existem diversos sítios arqueológicos, com uma variedade significativa de formas - cerâmicos, funerários e abrigos-sob-rocha -, com um número significativo de pinturas e gravuras, pertencentes a diversas tradições. As primeiras pesquisas arqueológicas na região tiveram início no final dos anos 1960, sendo intensificadas nos anos 1980. Sem pretender fazer uma apresentação exaustiva desse patrimônio arqueológico e das pesquisas realizadas na região, o que nos afastaria sobremaneira dos objetivos mais imediatos do presente artigo, nos limitaremos às pesquisas realizadas no sítio Furna do Estrago, um abrigo-sob-rocha, localizado no município do Brejo da Madre Deus. Nossa escolha justifica-se tanto pelo sítio estar localizado no Agreste Central de Pernambuco, área em que vem sendo realizada a pesquisa que deu origem ao presente artigo, quanto por tratar-se, provavelmente, do sítio arqueológico no Brasil que mais pesquisa gerou no campo da bioarqueologia (SOUZA, 2018).

O abrigo foi prospectado na década de 1980, pela arqueóloga Jeannette Maria Dias de Lima, que esteve ligada à Universidade Católica de Pernambuco. Antes das escavações, o sítio fora noticiado pelo arqueólogo Marcos Albuquerque, da Universidade Federal de Pernambuco, que documentou no local, em 1971, a ocorrência de pictografias (ALBUQUERQUE, 1971).

A primeira ocupação humana na Furna do Estrago teria ocorrido por volta de 11.000 anos (AP). O período em que foi usado como cemitério foi relativamente curto, entre 250 e 300 anos. Mas a descoberta desses sepultamentos - onde foram encontrados mais de 80 esqueletos, bem preservados - tem sido considerada um dos achados mais importantes da arqueologia no Brasil (SOUZA, 2018).

Os sepultamentos humanos ocupam um lugar de destaque no surgimento do comportamento simbólico. Sepultamentos com aproximadamente 100 mil anos, no sítio Qafzeh, em Israel, já apresentavam corpos com adornos e oferendas. Essas práticas são consideradas marcas de comportamento complexo simbólico, apresentando possibilidades significativas na análise dos grupos (ALLAN, ANDRADE, RANGEL, JR., 2015).

Voltando à Furna do Estrago, mais da metade dos esqueletos humanos ali encontrados foram sepultados em envoltórios de fibra vegetal, com algumas variações. A diferença no uso das palhas e esteiras em indivíduos adultos e crianças, além de outros aspectos referentes ao tipo de sepultamento, fornecem informações relevantes sobre os grupos que ocuparam o abrigo. Castro, que estudou os marcadores de identidades coletivas na materialidade desses sepultamentos, observou que "nos indivíduos adultos as esteiras e a palha foram utilizadas separadamente e também em conjunto; nas crianças foi constatado o uso predominante de esteiras, seguido da palha e do trançado" (CASTRO, p. 352). O tipo de trançado, a fibra utilizada e a recorrência desses 
nas três ocupações também foram analisados pela autora. Alguns objetos, no entanto, não tinham recorrência, sendo encontrados unicamente em alguns indivíduos, como instrumentos musicais, instrumentos de osso e instrumentos de madeira. Merece destaque uma flauta confeccionada a partir de uma tíbia humana, de 33 centímetros, encontrada junto a um dos esqueletos humanos, o chamado "flautista", que teve sua face reconstituída através da reconstrução facial forense.

Castro também analisou diferentes adornos que acompanhavam esses sepultamentos, como colares e pingentes, confeccionados em nove categorias de matéria-prima (conchas; ossos; pedras; dentes; ossos e dentes; ossos e conchas; ossos e pedras; sementes; ossos, conchas e pedras), predominando os colares de osso.

Analisando a literatura sobre o sítio, Sheila Souza (2018) apontou mais de 70 trabalhos, incluindo 14 dissertações de mestrado e 5 teses de doutorado, 30 artigos e algumas monografias. A autora observa, no entanto, que a maioria dos trabalhos se ocupa do cemitério, sendo a atenção aos diferentes usos do abrigo, suas transições e interrupções pouco estudadas. Em relação aos sepultamentos, em suas explorações de caráter cultural ou biológica, muitos estudos se limitariam a análises especializadas, dialogando pouco com outras pesquisas sobre o sítio. Além da falta de integração entre as pesquisas, a autora chama a atenção para a necessidade de projetos de caráter multidisciplinar.

[...] ainda que os projetos de bioarqueologia tenham se multiplicado no Brasil, e a abordagem de sítios com remanescentes humanos tenha podido ser cada vez mais técnica e sofisticada, tem sido evidente a necessidade de melhorar nossa capacidade de integração de equipes multidisciplinares que desenvolvam experiência específica neste tipo de testemunho (SOUZA, 2018, p. 51).

Finalmente, a bioarqueologia, para Souza, no contexto da Furna do Estrago, teria permitido algumas análises, alimentando 0 campo das discussões e das ideias, mas ainda não teria sido possível sua plena realização.

Plantas e bichos conversam com todas as dimensões do cemitério, e pedem mais diálogo. A Furna do Estrago, tal como outros sítios funerários já escavados, aguarda mais leituras, olhares para o que ainda não foi considerado, interpretado, descoberto [...] (ibid, p. 53)

\section{Considerações Finais}


O agreste pernambucano se apresenta como campo potencial para ampliação de pesquisas arqueológicas que possibilitem o estabelecimento de vínculos entre a comunidade regional e a academia. Essa possibilidade favorece o envolvimento das pessoas do entorno do sítio na realização, apropriação e divulgação das pesquisas. A capacidade de mobilização da população local revela uma característica inovadora e transformadora do projeto de pesquisa Educação Patrimonial e Cartografia Arqueológica do Agreste Central de Pernambuco.

Para contribuir com essa perspectiva de inovação, buscando, como postula Souza, o que ainda estar por ser considerado, interpretado e descoberto, assumimos a bioarqueologia como um dos pilares da pesquisa. Como procuramos demonstrar ao longo do texto, essa perspectiva abre novas possibilidades de conhecer mais sobre os antigos habitantes da região e suas formas de gestão da vida. Esse conhecimento, como já afirmamos, poderá nos ajudar a promover diálogos entre as formas de gestão da vida no passado e na atualidade, tendo como finalidade refletir sobre a colonialidade da vida e a perspectiva decolonial.

Nesse sentido, o Bem Viver pode ser considerado um exemplo de proposta de vida das sociedades originárias, que se concretiza através do Bem Conviver. Nas comunidades rurais, não obstante a grande influência sofrida pelo estilo de vida urbano, ainda sobrevivem várias experiências de vida em comunidade, sobretudo entre as populações tradicionais, que poderão ter em sua origem alguma influência dos antigos modelos de organização existente entre os antigos habitantes dessa região.

\section{Referências}

ALBUQUERQUE, M. 1971. "Nota prévia sobre a ocorrência de pictografias no Município de Brejo da Madre de Deus". Boletim do Instituto Joaquim Nabuco de Pesquisas Sociais 18: 107-134.

ALLAN, Allysson. ANDRADE, Fernando. RANGEL JR, Miguel José. Origem e Dispersão dos Humanos Modernos. In: NEVES, Walter Alves. RANGEL JR, Miguel José. MURRIETA, Rui Sergio S. Assim Caminhou a Humanidade. São Paulo: Palas Athena, 2015.

ARISTÓTELES. Política. Texto Integral. Tradução de Torrieri Guimarães. São Paulo: Martin Claret, 2003.

ARRUDA, Marcos. Economia solidária e o renascimento de uma sociedade humana matrística. Texto apresentado no Painel "Por Uma Economia Do Povo: Realidades e Estratégias Do Local Ao Global" - realizado no Fórum Social Mundial, Mumbai, Índia, 20/1/2004. Disponível em: http://alainet.org/active/5610\&lang=es.

CASTRO, Viviane Maria Cavalcanti. SÍTIO FURNA DO ESTRAGO, PE Práticas Funerárias e Marcadores de Identidades Coletivas. Clio Arqueologia. V33N2, p. 330$371,2018$. 
COSTA, Sérgio. (RE)ENCONTRANDO-SE NAS REDES? As ciências humanas e a nova geopolítica do conhecimento'. Estudos de Sociologia, Rev. do Progr. de PósGraduação em Sociologia da UFPE, v. 16, n. 2, p. 25 - 43.

CHOQUEHUANCA, David. 25 Postulados para o Bem Viver. La Paz, 2010.

Disponível em:

http://www.economiasolidaria.org/noticias/vivir_bien_propuesta_de_modelo_de_gobier no_en_bolivia. Acesso em 21 de agosto 2013.

DÁVALOS, Pablo. La democracia disciplinaria: El proyecto posneoliberal para América Latina. Quito: Ibéria, 2010.

FEITOSA, Saulo Ferreira. O Processo de Territorialização Epistemológica da

Bioética de Intervenção: Por uma Prática Bioética Libertadora. Tese (Doutorado em Bioética) - Programa de Pós-Graduação em Bioética da Universidade de Brasília. Brasília, 2015.

GROSFOGUEL, Ramón. Dilemas dos estudos étnicos norteamericanos: multiculturalismo identitário, colonização disciplinar e epistemologias descoloniais. In: Cienc. Cult. [online], 2007, vol. 59, n.2, pp. 32-35.

MATURANA, Humberto \& VERDEN-ZÖLLER, Gerda (1993). Amor y Juego: fundamentos olvidados de lo humano - desde el Patriarcado a la Democracia. 5. ed. Santiago de Chile: Editorial Instituto de Terapia Cognitiva, 1997.

PLATÃO. A República. Texto Integral. Tradução de Pietro Nassetti. 2. ed. São Paulo: Martin Claret, 2010.

QUIJANO, Aníbal 'COLONIALITY AND MODERNITY/RATIONALITY', Cultural Studies, 21: 2, $168-178$ To link to this Article: DOI: 10.1080/09502380601164353 URL: http://dx.doi.org/10.1080/09502380601164353. 2007.

SOLARI, Ana. PESSIS, Anne Marie. MARTIN, Gabriela. SILVA, Sérgio Francisco Serafim Monteiro da. Patologias Invisíveis na Bioarqueologia da Infância. Revista de Arqueologia, v. 31, n. 22018.

SOUZA, Sheila Mendonça de. Arqueologia Funerária e a Furna do Estrago. Clio Arqueologia. V33N2, p. 44-92, 2018.

People with dwarfism and cleft palate may have been revered in ancient times. Disponível em: www.sciencemag.org/news/2019/03/people-dwarfism-and-cleft-palatemay-have-been-revered-ancient-times. Pesquisa realizada em 13/04/2019.

PORTO-GONÇALVES, Carlos W. A colonialidade do saber: eurocentrismo e ciências sociais Perspectivas latino-americanas (Apresentação da edição em português). In: Lander, EDGARDO (Org.) A colonialidade do saber: eurocentrismo e ciências sociais Perspectivas latino-americanas. Colección Sur Sur, CLACSO, Ciudad Autónoma de Buenos Aires, Argentina. setembro 2005. 